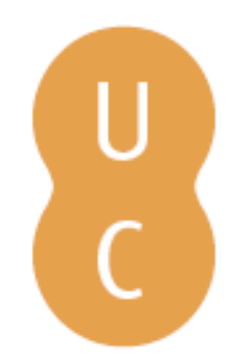

\title{
pommalina
}

\section{Uma nova realidade internacional: a caminho da descontinuidade da existência humana}

\author{
Autor(es): $\quad$ Martins, Marco António \\ Publicado por: Imprensa da Universidade de Coimbra \\ URL \\ persistente: URI:http://hdl.handle.net/10316.2/47436 \\ DOI: $\quad$ DOI:https://doi.org/10.14195/978-989-26-1524-0_12 \\ Accessed : $\quad$ 26-Apr-2023 12:29:00
}

A navegação consulta e descarregamento dos títulos inseridos nas Bibliotecas Digitais UC Digitalis, UC Pombalina e UC Impactum, pressupõem a aceitação plena e sem reservas dos Termos e Condições de Uso destas Bibliotecas Digitais, disponíveis em https://digitalis.uc.pt/pt-pt/termos.

Conforme exposto nos referidos Termos e Condições de Uso, o descarregamento de títulos de acesso restrito requer uma licença válida de autorização devendo o utilizador aceder ao(s) documento(s) a partir de um endereço de IP da instituição detentora da supramencionada licença.

Ao utilizador é apenas permitido o descarregamento para uso pessoal, pelo que o emprego do(s) título(s) descarregado(s) para outro fim, designadamente comercial, carece de autorização do respetivo autor ou editor da obra.

Na medida em que todas as obras da UC Digitalis se encontram protegidas pelo Código do Direito de Autor e Direitos Conexos e demais legislação aplicável, toda a cópia, parcial ou total, deste documento, nos casos em que é legalmente admitida, deverá conter ou fazer-se acompanhar por este aviso.

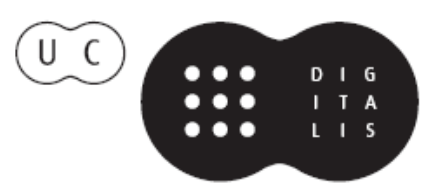


JOSÉ MANUEL PUREZA JOSÉ JUSTE RUIZ (COORDS.)
IMPRENSA DA

UNIVERSIDADE

DE COIMBRA

COIMBRA

UNIVERSITY

PRESS
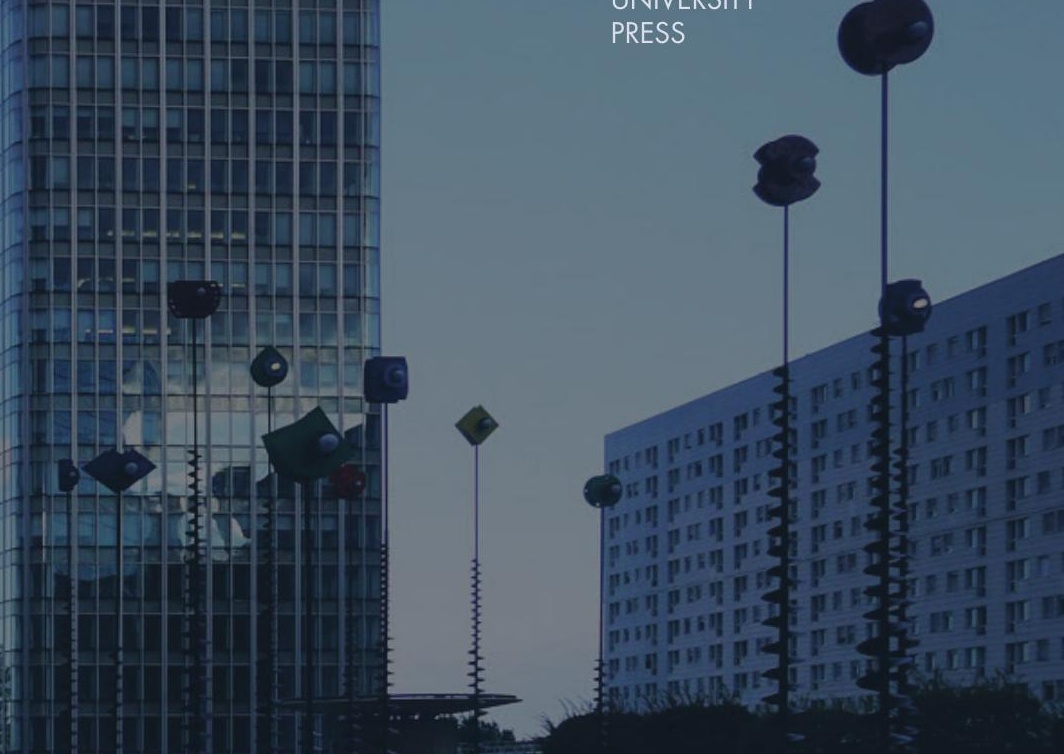

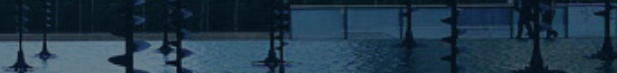

OS ESTADOS

EA ORDEM

INTERNACIONAL

CONTEMPORANEA

ATAS DO V ENCONTRO LUSO-ESPANHOL DE Professores de Direito internacional e RELAÇÕES INTERNACIONAIS 
UMA NOVA REALIDADE INTERNACIONAL:

A CAMINHO DA DESCONTINUIDADE DA

EXISTÊ NCIA HUMANA

Marco António Martins

O dia 17 de dezembro de 2010 ficará marcado no túnel do tempo histórico como o fatídico dia que viria a transformar parte do Médio Oriente e Norte de África num furor de esperança denominado de Primavera Árabe, em que na pacata cidade de Sidi Bouzid, geograficamente localizada a 260 quilómetros de Tunes, se assistira à imolação de fogo de um jovem de vinte e seis anos de idade, licenciado em informático, apesar de existir informação contrária de que apenas possuía o Baccalauréat, conhecido por Mohamed Bouazizi e considerado como o "pai da revolução tunisina" que pouco de antes de falecer a 4 de Janeiro de 2011 no hospital em Ben Arous, recebeu a visita do então Presidente Zine Ben Ali que posteriormente viria a ser destituído a 14 de Janeiro de 2011.

Tal ato, considerado de extremo desespero e violência, surtiu efeito por ter sido confiscado pelas autoridades o carrinho de venda ambulante de frutas e verduras a Bouazizi que a partir desse mesmo instante a sua memória refletir-se-ia como uma suspensão temporária do tempo presente localizado no futuro da sua vida que terminara, por decisão do poder vigente, o simples direito do direito à vida. 
Assim, Bouazizi após esgotadas inúmeras tentativas de reaver o seu único meio de sustento optara por deixar no ciberespaço, precisamente na sua página pessoal do Facebook, o testemunho direto na primeira pessoa do ato que viria mais tarde cometer, pedindo acima de tudo perdão à sua mãe e culpabilizando não só a realidade bem como o sistema vigente. Recordemos as suas palavras perpetradas no espaço virtual global comum:

“Minha mãe, eu estarei viajando, perdoe-me. A censura não é útil, eu estou perdido no meu caminho e não está na minha mão, perdoe-me minha mãe se desobedeci às suas palavras, culpabilize os nossos tempos e não a mim, eu estarei a ir e não regressarei, olha eu não chorei e as lágrimas não caem dos meus olhos. A censura não é útil em tempos de traição na terra do nosso povo. Eu estou doente, não na minha mente, por tudo aquilo que aconteceu. Eu estou a viajar e eu estou a perguntar quem lidera a viagem para esquecer." (Saqer, 2011).

A viagem iniciada por Bouazizi cujo ponto de origem se localizou na cessação do direito à vida e se projetou para a realidade virtual do ciberespaço, leia-se Facebook e Twitter, antes de transferir-se ou de regressar para o campo de batalha convencional no qual retomamos a célebre frase de Carl Von Clausewitz mas, na forma readaptada ao caso concreto ao referir que a "ciberguerra não é mais do que a continuação da guerra por outros meios".

Assim sendo, o cenário de crescente volatilidade sentido e vivido no Médio Oriente não só engendrou o ato, por ventura qualificado de inimaginável, de abate na lógica sequencial iniciada com Saddam Hussein por enforcamento (30 de Dezembro de 2006); Osama Bin Laden por operacionais da US Navy SEAL e da CIA ( 2 de Maio de 2011); ao ex-líder da Líbia Muammar Gaddafi, diga-se de passagem, 
profetizado pelas forças ocidentais da NATO sob o nome de Odisseia do Amanhecer, em alusão à Odisseia de Homero e concretizado pelos opositores domésticos, no dia 20 de Outubro de 2011 com transmissão via network structure, Youtube e Aljazeera, como também tem vindo a incentivar à criação de uma umma, de uma comunidade pautada pela defesa do direito à existência do ser humano com a dignidade que lhe advém contra regimes autoritários que possam instigar à pobreza extrema ou por outras palavras impedir a mera sobrevivência ou prática religiosa.

Paralelamente a esta Primavera Árabe que se encontra numa fase de transformação em Outono Árabe, ao considerar os recentes atentados por parte da Daesh em Beirute a 12 e o de Paris a 13 de novembro de 2015, envolvendo em cenário não um conflito mais sim uma guerra opondo o mundo dito de ocidental por razões não de ordem de sistemas políticos autoritários, mas por questões de liberalismo económico e incapacidade da elite política em conseguir responder eficazmente à velocidade comunicacional dos fluxos de informação numa perspectiva sistémica das relações internacionais que viajam entre inputs e outputs pelos ambientes externos e internos, tem vindo nos últimos tempos a interrogar-se sobre a perda de identidade e de valores humanos na necessidade imperativa de reatar o diálogo perdido entre a sociedade civil e o escol político para restaurar os direitos fundamentais da existência do ser humano que se prendem com o conceito da própria vida.

Nesse sentido, recordemos que monges tibetanos na província de Sichuan, como forma de protesto contra a atuação do regime chinês na intolerância a práticas religiosas no Tibete que tem levado à detenção e à condução de monges para estabelecimentos prisionais por alegadamente preparem um ataque bombista na sequência de uma explosão registada num edifício governamental a 26 de Outubro de 2011 na Prefeitura de Chandun no Tibete, decidiram seguir nas últimas semanas pelo sacrifício da própria vida, 
utilizando a emulação de fogo, mas à data tal facto não deteve o impacto que causara no Médio Oriente, registando somente o silêncio da comunidade internacional, visto tratar-se de um assunto doméstico (Raman, 2011).

Precisamente, os estigmas projetados para além do corpo humano na forma de factos nacionais potencialmente internacionalizáveis têm transformado o mapa mundi à escala global onde começamos a pressentir gradualmente a aplicabilidade da bomeorhesis nas relações internacionais pela aptidão que o sistema possui de se auto-transformar ou de mudar-se para um outro, apesar da tendência vigente da comunidade internacional que qualificaríamos aqui de triangular (EUA, França e Alemanha, e somente quando necessário incluir-se-á o Reino Unido) em efetuar os seus esforços de status quo entre a homeostase cujo objectivo visa precisamente a manutenção do sistema e a homeostática na capacidade de absorver sem modificar o mesmo sistema.

Aliás, verifica-se praticamente a inexistência de guerras que oponham dois ou mais estados mas que de acordo com o Hilderberg Institute for International Conflict Research na sua publicação Conflict Barometer (2013: 15) identificaram-se no ano de 2013 cerca de 414 conflitos políticos entre os quais 221 com recurso a violência, 20 guerras, e 45 conflitos de elevada intensidade violenta. Procura-se por conseguinte no equilíbrio mundial a manutenção do grau óptimo de instabilidade que o sistema enquanto estrutura evolutiva seja capaz de absorver sem colocar em causa o equilíbrio mundial de paz e segurança internacionais.

Note-se que a título comparativo, no ano de 1945, a seguir à Segunda Guerra Mundial, observámos apenas 83 conflitos comparativamente com o ano de 2013. Importa com certa nostalgia no quadro das relações internacionais recordar que outrora sempre que um estado declarava guerra a outro levava à cessação das relações entre ambos até à assinatura de um tratado que viria a restabelecer 
a ordem anterior, por outras palavras, procurava-se a guerra para obter paz, atualmente, requer-se a paz para provocar a guerra.

Hoje, recorre-se ao conflito para justamente não outorgar a possibilidade de surgir uma guerra, sendo os estragos ocorridos de forma cirúrgica numa espécie de teste à capacidade tecnológica de ponta existente em matar na minimização de danos colaterais, entenda-se perdas humanas civis inevitáveis, porque na maioria dos casos as mesmas servem de escudos humanos. Observemos que tendo em consideração que segundo Adriano Moreira todo o facto nacional pode ser potencialmente internacionalizável, referimos nesse caso que se evidencia por um lado a transferência parcelar do poder soberano para o ambiente externo e, por outro lado a continuidade do maquiavelismo que recorre sistematicamente à utilização da força para posteriormente (re)estruturar o normativismo internacional com impacto na ordem jurídica interna.

De facto, segundo as lições de Manuel García Morente expressas nos Fundamentos de Filosofia, não existe facto ou coisa neste mundo que não seja passível de tomada de posição, mesmo que esta consista em apenas transmitir a indiferença pela não-indiferença entre o não ser dos valores e o seu contravalor. Talvez a dificuldade do ser humano em protesto por não assumir a vontade tácita de uma minoria que advoga a descontinuidade da existência humana resida na compreensão dos direitos detidos na esfera armilar tendo presente, conscientemente, as mensagens contidas de distopia quer na Guerra das Salamandras de Karel Capek quer no Deus das Moscas de William Golding quanto à capacidade destruidora da humanidade e da correspondente perda de inocência.

O combate pela promoção de uma sociedade onde a liberdade venha a ser considerada como uma conquista e não meramente por um valor de indiferença, insere-se numa acepção nietzschiana na esfera da vontade de poder cuja decisão ou luta representa o desígnio do simples desejo de viver ou de morrer. Se por um lado, 
o ser humano pretende reconstruir a imagem não distorcida e projetada de uma realidade em conflito para o ambiente interior de cada um de nós pelo recurso aos mais diversos meios, do mundo físico à Web 2.0, por outro lado, o epicentro da realidade concreta localiza-se na concepção do ambiente externo como a imagem traçada pela diferença de dois mundos no quadro espácio-temporal do ser humano no qual se assiste à intensificação da imprevisibilidade de acontecimentos nacionais com impacto internacional pela inconstância constante da ordem internacional.

Acrescentamos que à data cerca de 1.4 milhões de computadores XO foram entregues e distribuídos em 35 países, dos quais Haiti, Afeganistão, Brasil e Uruguai em nome do programa One-LaptopPer-Child, promovido pelo anterior Secretário Geral da ONU, Kofi Annan e pelo Professor Nicholas Negroponte (Director do MIT Media Laboratory) em 2005, para que não seja um mero utilizador do ciberespaço, mas sim um programador dotado de conhecimento para abandonar a situação de exclusão na qual se deparava.

Anotemos que o Ruanda, desde Setembro de 2008, tem seguido esse programa que consiste na distribuição a 100.000 crianças de computadores portáteis da marca XO, para evitar que genocídios como aqueles praticados no passado opondo tutsis e hutus, concretamente em 1994, que teriam vitimado cerca de um milhão de seres humanos, apenas por cada uma das etnias representar a diferença na igualdade. Sublinhemos ainda que Jean Piaget defendia a esse título que a educação é capaz de salvar as sociedades de colapsos violentos e evitar dessa forma o surgimento de convulsões derivado da marginalização ou de exclusão ao acesso ao conhecimento.

Neste contexto, identificamos duas novas classes sociais, por um lado os info-incluídos e, por outro lado, os info-excluídos, acrescentando nesta última o factor de pobreza incitado pelos mercados internacionais e materializados politicamente. 
Efetivamente, a crescente interdependência e a complexidade crescente da vida, numa acepção teilhardiana, incita à aceleração da necessidade de refundar a ordem internacional onde se cruza e se confunde o exercício da legitimidade nos meios utilizados, na acepção de Giovanni Botero, em nome da razão de Estado com o estado da razão na conciliação do indivíduo com a continuidade da imagem observada e recordada na sua memória no túnel do tempo que lhe proporcionará no futuro uma identidade através da assimilação da mesma no domínio relacional decorrente da representação da imagem de si próprio do ambiente interno para o ambiente externo na nova dinâmica da conjuntura internacional.

Todavia, esta posição implica a noção tácita de continuidade na descontinuidade na diferenciação do real do irreal na (re)descoberta do verdadeiro papel do Homem no acompanhamento da evolução e dos mais variados processos de readaptação das relações internacionais.

Paralelamente, recordando os Six Livres de la République (1576) de Jean Bodin assistimos ao surgimento da tendência humanista em nome da unidade na diversidade pela promoção de assimilação de valores com o desiderato de reorganizar o aparelho de poder do estado para recuperar o equilíbrio, exorcizando os medos através de uma transmutação da mente. Este ideal democrático, em nome do exercício pleno de cidadania posiciona-se para além fronteiras, tendo dessa forma emergido uma onda de protesto à escala global contra a ordem vigente que apenas defende os interesses financeiros dos mercados internacionais e agências financeiras, entre outros, a Moody's, a Standard \& Poors (Média e Pobreza) e a Goldman Sachs, e cujos rostos invisíveis se redesenham em redor dos excluídos e marginalizados pelo próprio sistema.

Com efeito, o ser humano integrado tem vindo a evoluir no campo de percepção espácio-temporal na prossecução da garantia da sua sobrevivência, alertando -em nome da geração à rasca, dos indignados (Movimiento 15-Mayo), a marcha global do 15 de 
Outubro que envolveu mais de 650 cidades em 80 países, Ocupar Wall Street -o escol político/financeiro para uma única certeza de que a antiga ordem ruiu e exigindo assim a reposição da democracia no verdadeiro significado do termo, tal como fora proferido pelo discurso fundador de Péricles, como oração fúnebre, ao referir: "A nossa constituição política não segue as leis de outras cidades, antes lhes serve de exemplo. O nosso governo chama-se democracia, porque a administração serve aos interesses da maioria e não de uma minoria." (Moreira, 1995: 27).

Nesse sentido, Marshall McLuhan alertava para essa circunstância da possibilidade de um estado de implosão social resultante da ausência de identidade. Todavia, essa reposição baseia-se não só na mudança de paradigma como também no redesenhar de uma nova cartografia de valores humanos alicerçados na dimensão utópica do projeto de continuidade da existência humana que tendencialmente se encontra cada vez menos vulnerável à escala global, mas que verifica a incapacidade de dar continuidade ao welfare state no quadro da sustentabilidade do desenvolvimento económico conforme fora previsto por Gunnar Myrdal e que na óptica de Silvério Rocha Cunha (2007: 57), a democracia representativa tem dificuldades em responder derivado da sua relação para com o subsistema político económico.

Refira-se que o exercício de cidadania no direito à inclusão engloba na sua esfera de ação a cultura humana que no entender de Sigmund Freud, na obra L'Avenir d'une Illusion (1927), abrange não só o saber e o poder que o Homem adquirira como também todos os meios disponíveis para regular as relações entre os seres humanos. Se por um lado, no quadro da cultura humana é passível relacionar o poder na satisfação da necessidade humana ou na concretização do instinto de cada indivíduo, por outro lado emerge um novo factor que advirá necessariamente da imperatividade de proteger de impulsos agressivos os interesses de uma maioria governada em detrimento da imperfeição da condução do leme da minoria governante. 
Deste modo, um estado enquanto ator das relações internacionais por justamente se encontrar numa relação de linkage deve procurar aceitar na entrega do poder político que é exercido como assinala Adelino Maltez, nos Princípios de Ciência Política, não em nome particular mas colectivo, uma transferência da legitimidade governativa na conciliação da maioria pelo reforço do sentimento da dimensão utópica do projeto que não pretende distanciar a política da razoabilidade intrínseca à realidade funcional do sistema internacional, mas sim aproximar e explorar a relação entre o ser e o dever ser.

Nesse quadro, o escritor cubano Alejo Carpentier na sua obra El Reino de Este Mundo (1949), cujo cenário geográfico se localiza na ilha de Haiti, na forma de real-maravilhoso, desenha o retrato da realidade da relação entre o governante e o governado, opondo legitimamente a noção de liberdade à situação de escravatura em correlação com o exercício de autoridade tendo como pano de fundo paralelo a Revolução Francesa e a Revolução Haitiana, argumentando que a grandeza do Homem consiste em querer melhorar aquilo que de facto é na condição humana.

Acrescentaríamos ao conceito de condição humana a imagem observada da dimensão da metamorfose da vida que consiste em aceitar o fundamento da vida humana num contínuo processo de adaptação a novas realidades que colocam em evidencia a aceitação da não indiferença pela diferença do princípio que subjaz à possibilidade de revolta interior que se refletirá no outro lado do espelho da imagem do Homem na distinção da ideia de bem e de mal, da verdade da mentira que leva à interrogação numa óptica santo agostiniana de se saber se de facto a verdade é passível de gerar ou não o sentimento de ódio.

Aliás, tendo em consideração como advoga Miguel de Unamuno, na obra Do Sentimento Trágico da Vida, que ao nosso pensamento corresponderia de certa forma à nossa vida, a observação da realidade centrar-se-á perante a incerteza da inconstância da vida 
na sua própria conduta. Nesse caso, em situações de desequilíbrio ou de ameaça provenientes do ambiente externo para o ambiente interno, a interrogação edificar-se-á no domínio da racionalidade versus irracionalidade dos atos no quadro intemporal da vida humana com consequências para o sistema vivo no seu todo.

Aqui o fundamento da ação para legitimar o comportamento do indivíduo transpõe a esfera da crença religiosa, na procura da afirmação da personalidade individual, advindo sincronicamente o sentimento de medo e de culpa na materialização da consciência na condução do caminho transcendente interior por entre dois mundos paralelos, o visível e o invisível para de facto sentir a humanidade na personificação da vontade geral e não individual porque o que se encontra em causa não consiste na descrença do ideal democrático, mas sim na democracia sequestrada pelos mercados internacionais como refere Eduardo Galeano, numas das suas últimas intervenções no dia 24 de Maio de 2011, referente à concentração de protesto ocorrida durantes umas semanas na Puerta del Sol em Madrid e por toda a Espanha.

Por último, anotemos que os atos humanos acabam por moldar a sociedade, de forma consciente, tendo noção das implicações dos atos escolhidos na confluência da intervenção do destino e do acaso no princípio verum-factum na relação entre liberdade e sujeição ao liberalismo, apesar da incerteza reinante por um lado na possibilidade de não garantir o ponto de equilíbrio óptimo de instabilidade e, por outro lado, quanto à reação do estado e do mercado face ao caminho que se desenha de mudança de paradigma no sistema internacional, tendo como única certeza que nenhum estado, segundo Joseph Nye (2007), poderá deter a pretensão de assumir na hierarquia das potências o posição de potência global sem conjugar hard power com soft power para obter smart power que incorpora os instrumentos militares, diplomáticos, políticos, económicos, jurídicos e culturais, legitimando a continuidade da 
realpolitik nas relações internacionais na prossecução do legado maquiavélico, outorgando apenas uma imagem aparente de mudança de facto do mundo físico visível.

\section{Referências}

Armitage, R. L.; Nye, Joseph (2007), "A Smarter, More Secure America”, CSIS Commission on Smart Power, consultado em 15 de novembro de 2015, em http:// csis.org/files/media/csis/pubs/071106_csissmartpowerreport.pdf .

Cunha, Silvério Rocha (2007), "Problemas da cidadania numa era de compressão", in Carvalhais, I. E. Cidadania no pensamento contemporâneo. Estoril: Principia.

Ettighoffer, Denis (2008), Netbrain. Planète Numérique. Les batailles des nations savantes. Paris: Dunod.

Mhenni, Lina Ben (2011), La revolución de la dignidad. Barcelona: Ediciones Destino.

Moreira, Adriano. (1995), "O ideal democrático. O discurso fundador de Péricles", in Moreira, Adriano. ; Bugallo, Alejandro.; Albuquerque, Celso, Legado Político do Ocidente. O Homem e o Estado. Lisboa: Instituto Português da Conjuntura Estratégica: 27

Noya, Javier; Rodríguez, Beatriz (2010), Teorías sociológicas de la globalización. Madrid: Tecnos: 194-217.

Raman, (2011), "As Tibet simmers, monks targetted. The Pioneer", consultado a 18 de novembro de 2015, em https://groups.google.com/forum/\#!topic/talk.politics. tibet/RBBvOPWNKmc .

Saqer, Gaith (2011), "The last Facebook status update of Bouazizi who set him self on fire starting the Tunisian revolution, Arab Crunch". Consultado a 18 de novembro de 2015, em http://arabcrunch.com/2011/01/the-last-facebook-statusupdate-of-bouazizi-who-set-him-self-on-fire-marking-starting-the-tunisian-revolution. html. 
(Página deixada propositadamente em branco) 